\title{
Definição, Tipos e Funções de Regra: Uma Interpretação da Obra de B. F. Skinner
}

\author{
Dante Marino Malavazzi ${ }^{1}$ \\ Maria Eliza Mazzilli Pereira \\ Pontifícia Universidade Católica de São Paulo
}

\begin{abstract}
RESUMO - Este artigo tem por objetivo esclarecer a posição de B. F. Skinner sobre a definição, os tipos e as funções de regras no controle do comportamento humano. Para identificar publicações do autor sobre o assunto, foi realizada uma análise de três fontes de dados: (a) 295 referências de trabalhos de Skinner realizados entre 1930 e 2004; (b) o acervo de uma universidade; (c) índices remissivos de 17 livros do autor. Dezoito publicações foram identificadas. Embora seja possível apontar, na obra de Skinner, algumas funções de estímulo previstas para as regras (e.g., discriminativa, motivacional e alteradora da função de estímulos), o autor admite a existência de regras sem incluir suas eventuais funções no controle do comportamento. Ao mesmo tempo, Skinner apresenta critérios para diferenciar as regras, facilitando a pesquisa experimental sobre o tema.
\end{abstract}

Palavras-chave: comportamento governado por regras, comportamento, Skinner, Burrhus Frederic, 1904-1990

\section{Definition, Types, and Functions of Rules: An Interpretation of B. F. Skinner's Work}

\begin{abstract}
This paper aims to clarify B. F. Skinner's position on definition, types, and functions of rules on the control of human behavior. In order to identify the author's publications on the subject, we performed an analysis of three data sources: (a) 295 references of Skinner's work published between 1930 and 2004; (b) a collection of a university; (c) indexes of 17 of Skinner's books. Eighteen publications were identified. Although it is possible to point out some stimulus functions for rules in Skinner's work (e.g., discriminative, motivational, and function altering of stimuli), the author admits the existence of rules without including the eventual functions they might have on the control of behavior. Skinner also presents criteria to differentiate rules, facilitating experimental research on the theme.
\end{abstract}

Keywords: rule governed behavior, behavior, Skinner, Burrhus Frederic, 1904-1990

Em 1966, B. F. Skinner definiu regra como "estímulo especificador de contingência" (Skinner, 1966/1969, p. 148). Para ele, o falante pode instruir o ouvinte a agir de determinada forma, em vez de modelar o comportamento correspondente no repertório do interlocutor. A descrição de contingência "substitui" uma história de reforçamento ou de punição. Além disso, a regra apresentada pelo falante permite ao ouvinte agir como se uma discriminação tivesse sido estabelecida (Skinner, 1963/1969).

Nas décadas de 1980 e de 1990 , porém, alguns analistas do comportamento questionaram tanto a definição Skinneriana de regra (e.g., Catania, 1989) quanto a função discriminativa eventualmente exercida por uma descrição de contingência no controle do comportamento humano (e.g., Malott, 1989/2004). A seguir, serão descritas as principais divergências de consagrados analistas do comportamento a respeito do tema. Primeiro, em relação à definição de regra. Depois, quanto às possíveis funções exercidas por ela no controle do comportamento humano.

\section{Definição de Regra: Topográfica versus Funcional}

Glenn (1987) defendeu a identificação de uma regra sem relacioná-la a qualquer comportamento eventualmente

1 Endereço para correspondência: Rua Bartira, 387, São Paulo, SP, Brasil. CEP: 05.009-000.E-mail: dmmalavazzi@gmail.com governado por ela. Diz a autora: "Como eventos ambientais objetivos, regras devem ser especificáveis sem referência aos eventos que entram em relações funcionais com elas" (p. 30). Em razão disso, ela sugeriu dois critérios para classificar um estímulo verbal como regra. Tal estímulo deve especificar (a) pelo menos dois eventos e (b) a relação de dependência entre eles. Admitindo a possibilidade de os eventos especificados não envolverem respostas de um organismo (e.g., a lei científica $E=m \cdot c^{2}$ ), Glenn apresentou uma definição topográfica do conceito: "Regras são descrições de relações funcionais - universais, idiossincráticas ou específicas de uma cultura" (p. 31).

Catania (1989) discordou da definição proposta por Glenn (1987). Interessado nas possíveis funções de um estímulo antecedente verbal sobre o comportamento humano, o autor não considera a topografia de uma regra fundamental à compreensão do modo como ela afeta a resposta especificada na descrição de contingência. Segundo ele, "assim como não chamamos um estímulo de discriminativo se ele não tem efeito comportamental sobre um organismo, não devemos chamar um [estímulo] antecedente verbal de regra se ele não tem efeito comportamental sobre um ouvinte" (p. 50). Para o autor, portanto, a definição de regra exige identificar a função desse estímulo verbal no controle do comportamento humano.

Em resposta a Catania (1989), Glenn (1989) voltou a defender a possibilidade de se identificar uma regra independentemente de sua eventual função (e.g., 
discriminativa) sobre o comportamento humano, acirrando o debate topografia versus função. Mais uma vez, de acordo com Glenn, classificar um estímulo verbal como regra não requer a identificação prévia de qualquer efeito desse estímulo sobre o ouvinte. Ou, dito de outra maneira, a formulação de uma regra pelo falante não implica, necessariamente, qualquer controle sobre o comportamento do ouvinte.

\section{Funções de Regra: Discriminativa, Condicional, Motivacional e Alteradora de Função}

Conforme já assinalado, a divergência entre analistas do comportamento não se limita à definição de regra; ela se estende às suas possíveis funções no controle do comportamento humano. Entre elas, vale citar: (a) discriminativa (e.g., Skinner, 1963/1969), (b) condicional (e.g., Sério, 2002/2010), (c) motivacional (e.g., Malott, 1989/2004) e (d) alteradora da função de estímulos (e.g., Schlinger \& Blakely, 1987). A seguir, essas funções serão brevemente descritas - em ordem crescente de complexidade.

\section{Condicional}

Como a função discriminativa foi antecipada por Skinner (1963/1969) e será retomada na seção de Resultados e Discussão, cabe apresentar a função condicional proposta por Sério $(2002 / 2010)$. Na avaliação da autora, dada uma história de reforçamento diferencial tendo como critério a presença de uma regra, esta também pode conferir funções discriminativas diferenciais (SD ou $\mathrm{S} \Delta)^{1}$ aos estímulos antecedentes especificados na descrição de contingência, como ocorre em uma discriminação condicional. Dito de outra forma, a regra pode não representar o SD em uma contingência, mas determinar a função de $\mathrm{SD}$ ou de $\mathrm{S} \Delta$ dos estímulos antecedentes descritos por ela.

Entretanto, Sério (2002/2010) advertiu:

Como no caso de qualquer estímulo, não é a simples presença de uma descrição que produzirá alterações em nós; a descrição só produzirá alterações se tiver adquirido função de estímulo discriminativo ou de estímulo condicional por meio de reforçamento diferencial. (p. 174)

\section{Motivacional}

Para Malott (1989/2004), entretanto, uma regra controla o comportamento humano como uma operação motivadora (OM) e não como um estímulo discriminativo ou um estímulo condicional. Nesse sentido, a regra altera momentaneamente (a) o valor reforçador (positivo ou negativo) de um estímulo especificado na descrição de contingência e (b) a frequência de qualquer resposta ligada à produção ou à eliminação desse estímulo (cf. Laraway, Snycerski, Michael, \& Poling, 2003).

1 SD: Estímulo que aumenta a probabilidade de uma resposta ocorrer por ela ter sido reforçada em sua presença. $\mathrm{S} \Delta$ : Estímulo que diminui a probabilidade de uma resposta ocorrer por ela não ter sido reforçada em sua presença.

\section{Alteradora da Função de Estímulos}

Schlinger e Blakely (1987) propuseram a função alteradora da função de estímulos, a qual envolveria, entre outras, tanto a função condicional proposta por Sério (2002/2010) quanto a função motivacional sugerida por Malott (1989/2004). Entre as alterações da função de estímulos previstas pelos autores, cabe citar (a) mudanças na função evocativa de estímulos discriminativos ou de operações motivadoras, seja pelo estabelecimento de relações discriminativas ou motivadoras entre um evento antecedente e uma classe de respostas, seja pelo fortalecimento ou enfraquecimento de relações discriminativas ou motivadoras já existentes; (b) mudanças na função reforçadora (positiva ou negativa) de estímulos, seja pela atribuição de valor reforçador (positivo ou negativo) a um evento subsequente, seja pelo fortalecimento ou enfraquecimento de reforçadores já existentes; (c) mudanças na função eliciadora de estímulos, seja pelo estabelecimento de relações respondentes entre um evento antecedente e uma classe de respostas, seja pelo fortalecimento ou enfraquecimento de relações respondentes já existentes.

Dessa forma, no lugar da tradicional interpretação de regras com função discriminativa (e.g., Skinner, 1963/1969, 1966/1969), Blakely e Schlinger (1987) ressaltaram a função alteradora da função de estímulos. Isso porque, segundo os autores, há pelo menos três problemas em se classificar regras como estímulos discriminativos. O primeiro deles refere-se ao fato de um SD evocar uma respostas de determinada classe devido a uma história de reforçamento diferencial na sua presença. No entanto, quando ocorre um longo intervalo de tempo entre a apresentação de uma regra e a emissão da resposta especificada por ela, "esse efeito atrasado não se assemelha ao produzido por um SD" (p. 185). Ao mesmo tempo, argumentaram Blakely e Schlinger, classificar regras como estímulos discriminativos obscurece não apenas sua função alteradora da função de estímulos, mas também a similaridade entre regras e contingências inicialmente sugerida por Skinner (1966/1969). Nas palavras dos autores:

Tanto regras como contingências alteram as funções de estímulos e, assim, [alteram] as funções comportamentais envolvendo aqueles estímulos... Essa função de regras e contingências difere daquela dos SDs, os quais não alteram as funções de outros estímulos, mas apenas evocam o comportamento que no passado foi diferencialmente reforçado na sua presença. (p. 185)

\section{Objetivo e Justificativa}

Inspirado no debate sobre as definições e sobre as possíveis funções exercidas por regras no controle do comportamento humano, este artigo tem por objetivo esclarecer a posição de Skinner a respeito do tema, bem como diferenciar os tipos de regra examinados pelo autor. Dessa forma, espera-se (a) contribuir para a produção não experimental na Análise do Comportamento (Tourinho \& Sério, 2010), (b) corrigir eventuais interpretações equivocadas da visão de Skinner (Morris, Todd, Midgley, Schneider, \& Johnson, 1995) e (c) estimular novos estudos experimentais acerca do assunto (Dittrich, 2011). 


\section{Método}

A fim de identificar publicações de Skinner sobre o tema deste artigo (i.e., definição, tipos e funções de regras), três estratégias foram adotadas. Primeiro, a verificação de uma lista com 295 referências de trabalhos realizados por Skinner, de 1930 a 2004, publicada por Andery, Micheletto e Sério (2004). Depois, a consulta ao acervo de uma universidade que reúne a maioria dos trabalhos do autor. Por último, o exame dos índices remissivos de 17 livros de Skinner. Nas três fontes - lista, acervo e índices remissivos -, buscaram-se textos de Skinner em que o autor utilizou, ao tratar de definição, função ou tipo de regra, pelo menos uma das seguintes palavraschave: advice, command, contingency-shaped behavior, contingency-specifying stimuli, direction, instruction, law, maxim, proverb, rule, rule-governed behavior e warning. Como indicou a revisão da literatura realizada para este trabalho, esses termos geralmente são usados pelo autor ao discutir o comportamento governado por regra.

Juntas, as estratégias empregadas resultaram no levantamento de 18 publicações de Skinner acerca do tema. Entre elas, quatro artigos e 11 capítulos de livro, além de três entradas no livro Notebooks, organizado em parceria com R. Epstein ${ }^{2}$.

A leitura cronológica dessas publicações teve como objetivo responder às seguintes questões: (a) Qual a definição Skinneriana de regra?, (b) Quais as funções de estímulo previstas por Skinner ao interpretar o controle de regras sobre o comportamento humano?, (c) Quais os tipos de regra descritos por Skinner? e (d) O que diferencia os tipos de regra descritos por Skinner?

\section{Resultados e Discussão}

Para esclarecer a posição de Skinner a respeito das questões levantadas, citações $\operatorname{diretas}^{3}$ e paráfrases de trechos do autor são apresentadas em ordem cronológica e relacionadas, ao final de cada subtítulo desta seção, à divergência de visões registrada na Introdução.

\section{Definição de Regra}

No livro Contingencies of Reinforcement: A Theoretical Analysis, Skinner (1966/1969) definiu regra da seguinte forma: "Uma regra é simplesmente um objeto no ambiente" (p. 148) ou "um estímulo especificador de contingência" (p. 148). Enquanto objeto no ambiente ou descrição de contingência, uma regra não apresenta nenhuma função no controle do comportamento humano. Como será visto adiante, a eventual aquisição de função por uma regra pode ocorrer de duas formas: condicionamento respondente ou condicionamento operante, seja de maneira direta ou indireta. Dessa forma, vale salientar, Skinner (1963/1969, 1966/1969) apontou que a descrição de uma contingência

2 Nas Referências, essas 18 publicações são destacadas com um asterisco (*).

3 As citações diretas de Skinner são traduções do inglês para o português, feitas pelos autores deste artigo. pelo falante não implica, necessariamente, qualquer efeito sobre o comportamento do ouvinte. Em outras palavras, para adquirir função, a regra tem de ser direta ou indiretamente pareada a outros estímulos.

Feita essa ressalva, no livro About Behaviorism, Skinner (1974/1976) se opôs à formulação cognitivista do comportamento governado por regra, ao afirmar que as regras não estão nas contingências de reforçamento, mas são descrições delas. Não por acaso, 10 anos depois, Skinner (1984a) considerou equivocada a expressão extrair regras das contingências. Categórico, o autor novamente ressaltou: "As regras não estão nas contingências; elas são descrições de contingências" (p. 610). No mesmo ano, Skinner (1984b) voltou a sinalizar o equívoco dos cognitivistas ao assumirem que as regras estão nas contingências. Mais uma vez, afirmou: "Regras são comportamento verbal descritivo de contingências" (p. 660).

À primeira vista, a definição de regra apresentada por Glenn $(1987,1989)$ - a qual defende a identificação de uma regra sem incluir sua eventual função no controle do comportamento humano - aproxima-se mais da posição de Skinner (1963/1969, 1966/1969, 1974/1976, 1984a, 1984b) do que a formulação de Catania (1989), o qual rejeita a identificação de uma regra sem incluir sua função no controle do comportamento humano. Skinner admite a possibilidade de se identificar uma regra (i.e., uma descrição de contingência) sem fazer referência à sua eventual função no controle do comportamento humano.

\section{Tipos de Regra}

Ao longo de sua obra, Skinner também descreveu diferentes tipos de regra. Entre eles, comandos, leis, instruções, orientações, conselhos, avisos, provérbios e máximas. A seguir, será apresentado o desenvolvimento de cada um desses tipos na obra do autor.

Comandos. No livro Science and Human Behavior, Skinner (1953/1965) caracterizou um comando como estímulo verbal aversivo condicionado. Este pode afetar o ouvinte devido ao pareamento com consequências aversivas administradas pelo falante. Nas palavras de Skinner, "um comando simples é um estímulo aversivo - uma ameaça especificando a ação que produzirá fuga" (p. 236). Além de indicar a resposta a ser emitida pelo ouvinte, um comando produz um efeito: "ele gera uma condição aversiva da qual apenas aquele comportamento produzirá fuga" (p. 338).

Quatro anos depois, no livro Verbal Behavior, Skinner (1957/1992) incluiu o comando entre os tipos do operante verbal chamado mando. Ao fazer isso, mais do que lembrar as duas características já citadas desse tipo de regra (i.e., produzir uma condição aversiva no ouvinte e indicar a resposta a ser emitida por ele), Skinner apontou um terceiro aspecto do comando: especificar o reforçador a ser mediado pelo ouvinte ao falante. Em resumo, afirmou: "Quando o comportamento do ouvinte é assim reforçado por diminuir uma ameaça, a resposta do falante é chamada de comando" (p. 38).

Dar ordens ou emitir comandos deve ter sido uma das primeiras práticas verbais da espécie humana, sugeriu 
Skinner (1974/1976). Ao caracterizar esse tipo de regra em About Behaviorism, Skinner lembrou que o falante descreve a resposta a ser emitida pelo ouvinte e administra consequências aversivas caso o interlocutor não lhe obedeça: "O falante diz ao ouvinte o que ele deve fazer e arranja consequências aversivas sob as quais ele [o ouvinte] aprende a fazê-lo e a fazê-lo de novo sempre que a ordem for repetida" (p. 133).

Passados oito anos, Skinner (1982), mais uma vez, incluiu os comandos entre os primeiros tipos de regra formulados pela espécie humana. Novamente, destacou as consequências aversivas para o ouvinte, se este não emitir a resposta indicada pelo falante: "Um comando especifica o comportamento a ser executado e pelo menos implica as consequências aversivas de não executá-lo" (p. 6).

Ao que parece, o tipo de regra intitulado comando por Skinner (1953/1965, 1957/1992, 1974/1976, 1982) descreve contingências de reforçamento sociais, diferenciando-se pelo fato de (a) produzir uma condição aversiva no ouvinte; (b) implicar ou especificar o reforçador a ser mediado ao falante; (c) o falante administrar consequências aversivas ao ouvinte caso este não emita a resposta indicada no comando.

Leis. Um segundo tipo de regra descrito por Skinner (1953/1965) foi a lei. Assim como um comando, uma lei não apenas especifica a resposta a ser emitida pelo ouvinte, mas também indica (ou implica) a consequência relacionada à (não) emissão de tal resposta - em geral, uma consequência aversiva.

Skinner (1953/1965) também se questionou sobre como uma lei pode afetar o comportamento do ouvinte. O próprio autor sugeriu uma resposta, destacando o papel das consequências descritas nesse tipo de regra: "Uma lei é uma regra de conduta no sentido de que ela especifica as consequências de certas ações, as quais, por sua vez, 'governam' o comportamento" (p. 339).

É interessante notar como, em última análise, o seguimento de uma regra depende das consequências previstas nela. Ao descrever uma contingência, o falante indica ao ouvinte as implicações de ficar ou não sob controle da resposta verbal emitida por ele. No caso das leis, como apontado a seguir, às vezes o falante não tem controle sobre as consequências antecipadas na regra. Outras vezes, o falante tem controle sobre elas, administrando-as em benefício próprio, no curto prazo, ou em prol do ouvinte, no longo prazo.

Dito isso, Skinner (1966/1969) apresentou uma definição de lei semelhante à registrada em Science and Human Behavior: "A lei é uma descrição de práticas éticas, religiosas ou governamentais prevalentes" (p. 159). Independentemente da agência de controle (e.g., religião ou governo) responsável pela sua formulação, uma lei caracteriza-se por descrever contingências de reforçamento: "Ao codificar as práticas de uma cultura em elogio e em censura, assim como ao formular uma lei científica, estamos descrevendo contingências de reforçamento" (p. 159).

Como Skinner (1971/2002) observou no livro Beyond Freedom and Dignity, "uma regra ou lei inclui uma afirmação de contingências prevalentes, naturais ou sociais" (p. 114). Enquanto as leis científicas descrevem contingências de reforçamento naturais, as leis religiosas e governamentais codificam contingências de reforçamento sociais. A seguir, será descrito o desenvolvimento desses subtipos de lei na obra de Skinner.

Leis cientificas. De acordo com Skinner (1966/1969), diferentemente de um comando, uma lei científica não ordena ao ouvinte emitir uma dada resposta; "ela simplesmente descreve as contingências sob as quais certos tipos de comportamento terão certos tipos de consequências" (p. 158).

Sob o controle de leis científicas, argumentou Skinner (1974/1976), o comportamento de um indivíduo é mais eficaz: "A ciência leva-o além da experiência pessoal e além da amostra incompleta da natureza, inevitável numa única vida" (p. 138). Ao mesmo tempo, a maior eficácia de tal comportamento está relacionada ao fato de as leis científicas permitirem ao indivíduo ficar sob controle de consequências atrasadas - as quais, por si sós, não podem modelar ou manter o comportamento presente.

Skinner (1982) também aproximou as leis científicas de instruções, conselhos e máximas, por geralmente envolverem consequências naturais, e as afastou de leis religiosas e governamentais, por incluírem consequências sociais. "As 'leis' da ciência aludem a consequências naturais e estão, portanto, mais próximas dos conselhos, máximas e instruções do que das leis de religiões e governos", observou (p. 7).

Sete anos mais tarde, Skinner (1989a) ainda indicou como os cientistas formulam as leis da natureza: aliando experiência pessoal à experimentação. "Tanto da experiência como da experimentação vêm os experts, aqueles que ou se comportam de maneiras que foram modeladas e mantidas por contingências ou podem descrevê-las", afirmou (p. 93).

Leis religiosas e governamentais. Segundo Skinner (1974/1976), as leis religiosas e governamentais originamse de sanções sociais não codificadas. "Ao obedecer à lei, uma pessoa evita punição", observou (p. 136). Conforme registrado anteriormente, a diferença em relação às leis científicas está no tipo de contingência descrito: “As leis de religiões e governos codificam contingências de reforçamento mantidas por ambientes sociais. As leis da ciência descrevem contingências que prevalecem no ambiente à parte de qualquer ação humana deliberada" (pp. 137-138).

Passados 12 anos, Skinner (1986) fez uma afirmação contundente a respeito das leis religiosas e governamentais. Para ele, tais leis atendem, antes de mais nada, aos interesses das respectivas agências de controle, já que as consequências para os fiéis e para os cidadãos (e.g., paz de espírito e segurança) são atrasadas.

No livro Recent Issues in the Analysis of Behavior, Skinner (1989b) ainda ilustrou como as agências de controle arranjam contingências de reforçamento por meio de regras. Por exemplo, o governo lança mão de reforçadores negativos para enfraquecer comportamento indesejado (e.g., "Proibido estacionar"; p. 116) ou para fortalecer comportamento desejado (e.g., "Pague seus impostos e evite multas"; p. 116). A economia, por sua vez, utiliza reforçadores positivos (e.g., dinheiro) para os trabalhadores cumprirem os acordos feitos. "As contingências requerem dispositivos verbais, tais como preços e contratos, os quais estão além do alcance de outras espécies", destacou (p. 117). Já a religião prevê consequências para o comportamento dos fiéis após a morte, conferindo a autoridades (e.g., bispos e cardeais) controle 
parcial das contingências de reforçamento dos fiéis durante a vida.

Em suma, o tipo de regra nomeado lei por Skinner (1953/1965, 1966/1969, 1971/2002, 1974/1976, 1982, 1986, 1989a, 1989b) distingue-se por descrever contingências de reforçamento naturais ou sociais prevalentes. Enquanto as leis científicas se referem a consequências naturais da interação do indivíduo com o ambiente, tornando seu comportamento mais eficaz, as leis religiosas e governamentais aludem a consequências sociais, atendendo primeiramente aos interesses das agências de controle (e.g., religião e governo) responsáveis por sua formulação.

Instruções e orientações. Um terceiro tipo de regra descrito por Skinner (1953/1965) foi a instrução ou orientação. Ao instruir o ouvinte, o falante pode alterar a probabilidade de uma resposta verbal ou não verbal do interlocutor. Aqui, conforme já discutido anteriormente, vale registrar mais uma vez a possibilidade de uma regra afetar o comportamento do ouvinte, mas não a obrigatoriedade de tal efeito.

Observação à parte, Skinner (1966/1969) também afirmou que a modelação é uma espécie de instrução ou de orientação: "Quando mostramos a alguém como fazer alguma coisa, compomos um modelo imitativo. Isso é um tipo de instrução ou orientação" (p. 163).

Em About Behaviorism, porém, Skinner (1974/1976) detalhou esse tipo de regra. Para ele, além de especificar a resposta a ser emitida pelo ouvinte e implicar uma consequência positiva (não administrada pelo falante), uma instrução ou uma orientação acrescenta à descrição o "ambiente controlador" (p. 133) da resposta a ser emitida pelo ouvinte. Como esclareceu o autor, uma instrução é elaborada para tornar desnecessária uma orientação posterior. Tais estímulos verbais não transmitem conhecimento, tampouco comunicam informação. Ainda assim, permitem uma aprendizagem mais rápida e segura por parte do ouvinte, ao colocá-lo sob controle de contingências específicas, responsáveis pela modelagem e manutenção de seu comportamento.

Conselhos e avisos. Em Verbal Behavior, Skinner (1957/1992) ainda analisou outros tipos de regra. Entre eles, conselhos e avisos. Em ambos, o ouvinte pode se beneficiar das consequências descritas pelo falante, embora este não seja responsável por sua administração.

No entanto, há uma distinção clara entre conselhos e avisos: "Quando estas [as consequências descritas] consistem em reforçamento positivo, chamamos o mando de conselho (Vá para o oeste!). Quando ao emitir o comportamento especificado pelo falante o ouvinte foge de estimulação aversiva, chamamos o mando de aviso (Atenção!)" (Skinner, 1957/1992, p. 40).

No livro Contingencies of Reinforcement: A Theoretical Analysis, Skinner (1966/1969) diferenciou conselhos e comandos. No primeiro caso, conforme indicado anteriormente, o falante especifica ao ouvinte as consequências positivas de uma determinada resposta, mas não é responsável por sua administração. No segundo caso, o falante indica e administra ao ouvinte as consequências aversivas de não emitir uma dada resposta.
Skinner (1974/1976) também ressaltou a principal diferença entre avisos e comandos, isto é, o fato de que as consequências aversivas descritas ou implícitas nos avisos são naturais (não arranjadas pelo falante): “'Cuidado!' descreve um ato e implica uma consequência, como escapar de uma pedra em queda, mas a última é um resultado natural do comportamento em vez de um resultado arranjado pelo falante" (p. 133). Ao mesmo tempo, lembrou que um conselho especifica a resposta a ser emitida pelo ouvinte e implica uma consequência positiva não administrada pelo falante.

Seis anos depois, no livro Notebooks, Skinner (1980) resgatou a definição de aviso apresentada em outras obras (e.g., Verbal Behavior e About Behaviorism). Assim, enfatizou que o falante avisa o ouvinte sobre as consequências aversivas de uma dada resposta, mas não é responsável por sua administração. Nas palavras de Skinner, "um aviso é uma regra relacionada a consequências aversivas; ele clarifica as contingências naturais, mas não adiciona consequências aversivas artificiais, como seria feito, por exemplo, ao se tornar o fumar ilegal" (p. 36). Posteriormente, Skinner (1989a) voltou a apontar o aspecto comum entre conselhos e avisos: "Conselhos e avisos colocam consequências naturais em jogo" (p. 89).

Em resumo, os tipos de regra denominados conselho e aviso por Skinner (1957/1992, 1966/1969, 1974/1976, 1980, 1989a) descrevem contingências de reforçamento naturais. Porém, enquanto um conselho indica a resposta a ser emitida pelo ouvinte para produzir um reforçador positivo natural, um aviso especifica a resposta a ser emitida pelo ouvinte para evitar/eliminar um reforçador negativo natural.

Provérbios e máximas. Skinner (1963/1969) definiu provérbios e máximas como descrições de contingências de reforçamento naturais ou sociais. "Aqueles que os observam [os provérbios e as máximas] ficam sob controle mais efetivo de seu ambiente", sublinhou (p. 123). Uma característica especial desse tipo de regra, acrescentou Skinner (1966/1969), é o fato de descrever contingências duradouras, passíveis de transmissão entre indivíduos. "Uma vez descobertas, elas [as máximas] podem ser transmitidas para e usadas por outros", pontuou (p. 163).

Do mesmo modo, Skinner (1974/1976) destacou a possibilidade de provérbios e máximas serem transmitidos "de geração a geração porque as contingências que eles descrevem são duradouras" (p. 135). Além disso, pontuou, tais estímulos verbais são úteis para fortalecer comportamentos marcados por consequências atrasadas: "Folclore, máximas e provérbios em geral são especialmente efetivos porque muitas das vantagens do comportamento que eles fortalecem são atrasadas e não funcionam bem como reforçadores" (p. 135).

Passados seis anos, Skinner (1980) incrementou a definição de provérbios, referindo-se a eles como "descrições metafóricas de contingências" (p. 326), cujos objetos concretos auxiliam o ouvinte na memorização e na "visualização" da contingência descrita. Em "Contrived Reinforcement", ainda os definiu como "conselhos generalizados, acumulados e transmitidos por culturas" (Skinner, 1982, p. 7). 
Em síntese, o tipo de regra nomeado provérbio e máxima por Skinner (1963/1969, 1966/1969, 1974/1976, 1980, 1982) descreve contingências de reforçamento naturais ou sociais, mas necessariamente duradouras. Esta característica permite sua transmissão de geração a geração, sendo útil para fortalecer comportamentos marcados por consequências atrasadas, com o auxílio de metáforas às vezes.

\section{Funções de Regra}

A leitura dos textos de Skinner selecionados para análise neste artigo permitiu identificar pelo menos três funções de estímulo sinalizadas pelo autor ao explicar o controle de regras sobre o comportamento humano: (a) discriminativa, (b) motivadora e (c) alteradora da função de estímulos. A seguir, serão apresentadas citações de Skinner para fundamentar essa interpretação.

Discriminativa. Nos capítulos “Operant Behavior" e "An Operant Analysis of Problem Solving”, Skinner (1963/1969, 1966/1969) recorreu ao conceito de estímulo discriminativo para explicar como uma regra controla o comportamento do ouvinte. Segundo o autor, uma regra pode ter função discriminativa em uma tríplice contingência. Contudo, ele alertou que a descrição de contingência, feita pelo falante, raramente tem o mesmo efeito sobre o ouvinte que a exposição direta às contingências de reforçamento - seja devido à imprecisão das regras apresentadas pelo falante, seja pela limitação das regras posteriormente formuladas pelo próprio ouvinte (i.e., autorregras).

Nas palavras de Skinner (1963/1969), “um indivíduo raramente descreve fielmente o modo como de fato foi reforçado. Mesmo quando foi treinado a identificar algumas contingências simples, ele pode não descrever uma nova contingência, particularmente quando esta é complexa" (p. 115). Ainda assim, sublinhou Skinner (1966/1969), uma regra elaborada pelo falante pode facilitar o estabelecimento, a manutenção e a "recordação" (p. 138) de uma discriminação por parte do ouvinte.

No entanto, de acordo com Skinner (1963/1969), uma explicação adequada sobre como uma regra controla o comportamento do ouvinte também exige identificar o reforço responsável pela modelagem do comportamento em questão (i.e., a resposta especificada na regra), bem como pelo estabelecimento do controle de estímulos sobre ele (i.e., discriminação tendo a regra como SD). Nas palavras de Skinner (1966/1969), "como um estímulo discriminativo, uma regra é efetiva como parte de um conjunto de contingências de reforçamento. Uma especificação completa deve incluir o reforçamento que modelou a topografia de uma resposta e a colocou sob controle do estímulo" (p. 148).

Motivacional. Um tipo específico de regra, o comando, ilustra essa função. Skinner (1953/1965) o definiu como um estímulo verbal aversivo condicionado: "Um comando simples é um estímulo aversivo - uma ameaça - especificando a ação que produzirá fuga" (p. 236). Nesse sentido, ele pode ser caracterizado como operação motivadora condicionada reflexiva (Laraway et al., 2003). Isso porque, ao produzir uma condição aversiva no ouvinte, (a) estabelece-se como reforçador negativo e (b) evoca qualquer resposta responsável por sua eliminação, sobretudo a resposta indicada no comando (Sundberg, 1993).

Ao mesmo tempo, o comando mostra como uma descrição de contingência apresentada pelo falante - isto é, um “objeto do ambiente" (Skinner, 1966/1969, p. 148) pode adquirir função de estímulo (i.e., motivadora) devido ao pareamento direto com outros estímulos, a saber, as consequências aversivas administradas pelo falante devido ao não seguimento da ordem. Antes desse pareamento, o comando apresentado pelo falante, cabe supor, não tem efeito sobre o ouvinte. Trata-se apenas de um evento e não de um estímulo. Uma vez condicionado, porém, o ouvinte fica sob controle da regra enunciada pelo falante. Dessa forma, evita a punição ministrada pelo último. Logo, o comportamento do ouvinte de obedecer ao comando do falante é negativamente reforçado. Em ocasiões futuras, diante de outras ordens, é mais provável que o ouvinte volte a obedecê-las. Afinal, conforme já sinalizado, a regra pode adquirir função de reforçador negativo condicionado, evocando qualquer resposta ligada à sua eliminação.

Alteradora da função de estímulos. Discutindo o possível efeito de outro tipo de regra (i.e., o aviso), Skinner (1953/1965) citou a diminuição da probabilidade de um ouvinte tocar uma superfície quente após ser informado sobre sua temperatura. Para o autor, o aviso tem "um efeito similar ao do condicionamento respondente" (p. 410).

Tal efeito, à primeira vista, é melhor explicado pela chamada alteração da função de um evento (e.g., superfície de um objeto) do que pela função motivadora. Nesse caso, o aviso do falante (a) diminui a probabilidade de respostas do ouvinte de uma dada classe (i.e., tocar a superfície de um objeto) porque (b) "atribui" valor reforçador negativo (i.e., temperatura elevada) a um evento (i.e., superfície de um objeto). Dessa forma, a alteração de função do evento não resulta de um condicionamento (respondente ou operante) direto. Em vez disso, decorre de uma operação verbal (i.e., aviso) por parte do falante.

Supondo que o falante tenha dito ao ouvinte "Cuidado! A superfície deste objeto está quente. Se você encostar nela, irá se queimar", a probabilidade de o ouvinte encostar em tal objeto tende a ser menor, uma vez que o objeto pode "adquirir" propriedade aversiva em razão do aviso do falante. Essa possível alteração de função do objeto talvez seja explicada pelo conceito de classe de estímulos equivalentes (cf. Sidman, 1994), como se a palavra quente enunciada pelo falante estivesse funcionalmente relacionada à experiência prévia do ouvinte, seja ela direta ou indireta, com superfícies quentes. Ao avisá-lo sobre a temperatura elevada do objeto em questão, o falante adicionaria temporariamente um novo elemento à classe de estímulos quente do ouvinte, evocando o comportamento de esquiva correspondente. Mais uma vez, ao ficar sob controle da regra apresentada pelo falante, o ouvinte evitaria um estímulo reforçador negativo, aumentando a probabilidade de seguir outras regras no futuro.

Originalmente sugerido por Skinner (1953/1965), o "efeito similar ao do condicionamento respondente" (p. 410) parece ter sido incluído na formulação de Schlinger e Blakely (1987) ao diferenciarem as funções discriminativa e motivadora de uma regra daquela alteradora da função de estímulos. Esta, segundo os autores, resgata a semelhança funcional entre 
contingências e regras inicialmente proposta por Skinner $(1953 / 1965,1966 / 1969)$ ao indicar a possibilidade de as descrições de contingências estabelecerem e/ou alterarem as funções (e.g., eliciadora, discriminativa, motivacional ou reforçadora) dos estímulos que compõem as regras.

De modo semelhante, no livro Cumulative Record: Definitive Edition, Skinner (1959/1999) admitiu a possibilidade de uma regra (e.g., juízo de valor) alterar o valor reforçador de um estímulo. Dessa vez, o exemplo usado pelo autor foi a mudança do valor reforçador positivo de morangos, os quais podem causar erupções cutâneas àqueles que os consomem, quando tais inflamações da pele são consideradas vergonhosas por meio de regras.

Sobre a alteração do valor reforçador de um estímulo promovida por uma descrição de contingência, Skinner (1959/1999) afirmou:

O efeito observável de qualquer juízo de valor é o de alterar a efetividade relativa de reforçadores [ênfase adicionada]. Podemos não apreciar mais os morangos por pensar a respeito da erupção cutânea. Se erupções cutâneas são consideradas suficientemente vergonhosas, ilegais, pecaminosas, mal-ajustadas ou imprudentes, podemos ficar satisfeitos quando empurramos os morangos para o lado numa grandiosa resposta de esquiva que produziria um sorriso nos lábios de Murray Sidman. (p. 35) Mais uma vez, a proposta de Schlinger e Blakely (1987) parece se aproximar da formulação original de Skinner (1959/1999), uma vez que a alteração no valor reforçador de um estímulo (e.g., morangos) resulta de uma regra (e.g., juízo de valor) e não de um condicionamento direto (respondente ou operante) envolvendo tal estímulo. Isto é, mesmo sem uma experiência aversiva direta com morangos, estes podem ter seu valor reforçador positivo transformado em negativo devido a uma operação verbal específica de uma determinada cultura.

Na mesma linha, ao analisar um romance policial no livro Notebooks, Skinner (1980) também sugeriu a alteração da função de um evento por causa da formulação de uma regra. Interrogada por um detetive, uma empregada doméstica teria se negado a sentar na cadeira do ex-patrão pelo fato de este ter cometido suicídio. Para Skinner, "a formulação que explica 'por que eu [a empregada doméstica] não quero me sentar na cadeira' confere ao sentar muito mais consequências aversivas e, por isso, torna-o menos provável" (p. 190).

Novamente, uma descrição de contingência (a) diminui a probabilidade de uma classe de respostas (i.e., sentar na cadeira) por (b) "atribuir" valor reforçador negativo a um evento (i.e., cadeira). Tal efeito, vale sublinhar, não resulta de um condicionamento respondente ou operante direto, mas de uma regra formulada pelo falante (i.e., empregada doméstica) na relação com o evento (i.e., cadeira). Daí, talvez, a seguinte afirmação de Skinner (1980): “As vantagens práticas de clarificar contingências por meio da formulação de regras têm seu paralelo no fortalecimento do estímulo condicionado" (pp. 189-190).

Portanto, a análise de alguns textos de Skinner (e.g., $1953 / 1965,1959 / 1999,1963 / 1969,1966 / 1969,1980)$ sugere ao menos três funções de uma regra no controle do comportamento humano: discriminativa, motivadora e alteradora da função de estímulos.

\section{Conclusão}

Entre os objetivos de uma pesquisa histórico-conceitual na Análise do Comportamento, Morris et al. (1995) e Tourinho (1999) destacam o esclarecimento teórico da disciplina. Esta pesquisa parece atendê-lo ao clarificar a posição de Skinner quanto à definição, aos tipos e às funções de regra previstas pelo autor, indicando o valor da produção não experimental na Análise do Comportamento (Tourinho \& Sério, 2010).

Nesse sentido, cabe ressaltar: embora seja possível identificar na obra de Skinner (e.g., 1953/1965, 1959/1999, 1963/1969, 1966/1969, 1980) algumas funções de estímulo previstas para as descrições de contingências de reforçamento (e.g., discriminativa, motivadora e alteradora da função de estímulos), o autor (1966/1969, 1974/1976, 1984a, 1984b) admite a existência de regras sem incluir suas eventuais funções no controle do comportamento humano. Dito de outra maneira, a apresentação de uma regra pelo falante não implica, necessariamente, controle sobre o comportamento do ouvinte.

Nesse sentido, conforme sugerido anteriormente, a formulação topográfica de Glenn $(1987,1989)$ está mais próxima da definição Skinneriana de regra do que a posição funcional de Catania (1989) - para quem o termo regra deveria ser reservado a estímulos verbais com qualquer função sobre o comportamento do ouvinte. Diferentemente deste, tanto Skinner (1953/1965, 1959/1999, 1963/1969, 1966/1969, 1980) quanto Glenn apontam a necessidade de condicionamento respondente ou operante (direto ou indireto) para uma regra controlar o comportamento do ouvinte. Do contrário, ela permanecerá um “objeto do ambiente”, isto é, não terá qualquer efeito sobre o interlocutor.

Ao mesmo tempo, se a interpretação da obra de Skinner feita nesta pesquisa estiver correta do ponto de vista conceitual, devem-se questionar as posições de Malott (1989/2004) - para quem Skinner não teria atribuído às regras a função motivadora - e de Blakely e Schlinger (1987) - para quem Skinner teria obscurecido a função alteradora da função de estímulos das regras ao lhes conferir função discriminativa. Como sublinhou Micheletto (2004), esses questionamentos representam uma das principais contribuições de uma investigação histórica, por colocarem em xeque visões normativas de um autor fundamental à Análise do Comportamento.

Por fim, ao apresentar o desenvolvimento de diferentes tipos de regra na obra de Skinner, este estudo contribui para o levantamento dos critérios pelos quais o autor os diferencia (e.g., 1953/1965, 1957/1992, 1963/1969, 1966/1969, 1971/2002, 1974/1976, 1980, 1982, 1986, 1989a, 1989b), favorecendo o ensino e a pesquisa de tal conteúdo pelos analistas do comportamento (Dittrich, 2011). Assim, esperase ter esclarecido, em alguma medida, a posição de Skinner sobre o conceito de regra.

\section{Referências}

Andery, M. A. P. A., Micheletto, N., \& Sério, T. M. A. P. (2004). Publicações de B. F. Skinner: de 1930 a 2004. Revista Brasileira de Terapia Comportamental e Cognitiva, 6, 93-134. 
Blakely, E., \& Schlinger, H. D. (1987). Rules: Function-altering contingency specifying stimuli. The Behavior Analyst, 10, 183-187.

Catania, A. C. (1989). Rules as classes of verbal behavior: A reply to Glenn. The Analysis of Verbal Behavior, 7, 49-50.

Dittrich, A. (2011). Possibilidades de investigação conceitual/ filosófica na análise do comportamento. Interação em Psicologia, 15, 27-33.

Glenn, S. S. (1987). Rules as environmental events. The Analysis of Verbal Behavior, 5, 29-32.

Glenn, S. S. (1989). On rules and rule-governed behavior: A reply to Catania's reply. The Analysis of Verbal Behavior, 7, 51-52.

Laraway, S., Snycerski, S., Michael, J., \& Poling, A. (2003). Motivating operations and terms to describe them: Some further refinements. Journal of Applied Behavior Analysis, $36,407-414$.

Malott, R. W. (2004). The achievement of evasive goals: Control by rules describing contingencies that are not direct acting. Em S. C. Hayes (Ed.), Rule-governed behavior: Cognition, contingencies, and instructional control (pp. 269-319). Oakland, CA: Context Press. (Trabalho original publicado em 1989)

Micheletto, N. (2004). Notas sobre uma análise histórica do behaviorismo radical. Em C. E. Costa et al. (Orgs.), Primeiros passos em análise do comportamento e cognição (Vol. 2, pp. 11-20). Santo André, SP: ESETec.

Morris, E. K., Todd, J. T., Midgley, B. D., Schneider, S. M., \& Johnson, L. M. (1995). Conclusion: Some historiography of behavior analysis and some behavior analysis of historiography. Em J. T. Tood \& E. K. Morris (Eds.), Modern perspectives on B. F. Skinner and contemporary behaviorism (pp. 195-215). Londres: Greenwood.

Schlinger, H. D., \& Blakely, E. (1987). Function-altering effects of contingency specifying stimuli. The Behavior Analyst, 10, 41-45.

Sério, T. M. A. P. (2010). Comportamento verbal e o controle do comportamento humano. Em T. M. A. P. Sério, M. A. P. A. Andery, P. S. Gioia \& N. Micheletto (Orgs.), Controle de estímulos e comportamento operante: Uma (nova) introdução (pp. 153-179). São Paulo, SP: EDUC. (Trabalho original publicado em 2002)

Sidman, M. (1994). Equivalence relations and behavior: A research story. Boston, MA: Authors Cooperative.

*Skinner, B. F. (1965). Education. Em B. F. Skinner, Science and human behavior (pp. 402-412). New York: The Free Press. (Trabalho original publicado em 1953)

* Skinner, B. F. (1965). Government and law. Em B. F. Skinner, Science and human behavior (pp. 333-349). New York: The Free Press. (Trabalho original publicado em 1953)

* Skinner, B. F. (1965). "Self-control”. Em B. F. Skinner, Science and human behavior (pp. 227-241). New York: The Free Press. (Trabalho original publicado em 1953)
*Skinner, B. F. (1969). An operant analysis of problem solving. Em B. F. Skinner, Contingencies of reinforcement: A theoretical analysis (pp. 133-171). New York: Appleton-Century-Crofts. (Trabalho original publicado em 1966)

*Skinner, B. F. (1969). Operant behavior. Em B. F. Skinner, Contingencies of reinforcement: A theoretical analysis (pp. 105-132). New York: Appleton-Century-Crofts. (Trabalho original publicado em 1963)

*Skinner, B. F. (1976). Causes and reasons. Em B. F. Skinner, About behaviorism (pp. 132-150). New York: Random House. (Trabalho original publicado em 1974)

*Skinner, B. F. (1980). Paternalism. Em B. F. Skinner \& R. Epstein (Eds.), Notebooks (pp. 35-36). Englewood Cliffs, NJ: PrenticeHall.

*Skinner, B. F. (1980). Proverbs. Em B. F. Skinner \& R. Epstein (Eds.), Notebooks (p. 326). Englewood Cliffs, NJ: PrenticeHall.

*Skinner, B. F. (1980). Rules more powerful than contingencies? Em B. F. Skinner \& R. Epstein (Eds.), Notebooks (pp. 189-190). Englewood Cliffs, NJ: Prentice-Hall.

*Skinner, B. F. (1982). Contrived reinforcement. The Behavior Analyst, 5, 3-8.

*Skinner, B. F. (1984a). Contingencies and rules. The Behavioral and Brain Sciences, 7, 607-613.

*Skinner, B. F. (1984b). Representations and misrepresentations. The Behavioral and Brain Sciences, 7, 655-667.

*Skinner, B. F. (1986). What is wrong with daily life in the western world? American Psychologist, 41, 568-574.

*Skinner, B. F. (1989a). The behavior of the listener. Em S. C. Hayes (Ed.), Rule-governed behavior: Cognition, contingencies, and instructional control (pp. 85-96). New York: Plenum Press.

*Skinner, B. F. (1989b). A new preface to Beyond Freedom and Dignity. Em B. F. Skinner, Recent issues in the analysis of behavior (pp. 113-120). Columbus, OH: Merrill Publishing Company.

*Skinner, B. F. (1992). The mand. Em B. F. Skinner, Verbal behavior (pp. 35-51). Cambridge, MA: Copley Custom Textbooks. (Trabalho original publicado em 1957)

*Skinner, B. F. (1999). Some issues concerning the control of human behavior. Em B. F. Skinner, Cumulative record: Definitive edition (pp. 25-38). Acton, CA: Copley Publishing Group. (Trabalho original publicado em 1959)

*Skinner, B. F. (2002). Values. Em B. F. Skinner, Beyond freedom and dignity (pp. 101-126). New York: Alfred A. Knopf. (Trabalho original publicado em 1971)

Sundberg, M. L. (1993). The application of establishing operations. The Behavior Analyst, 16, 211-214.

Tourinho, E. Z. (1999). Estudos conceituais na análise do comportamento. Temas em Psicologia, 7, 213-222.

Tourinho, E. Z., \& Sério, T. M. A. P. (2010). Definições contemporâneas da análise do comportamento. Em E. Z. Tourinho \& S. V. Luna (Orgs.), Análise do comportamento: Investigações históricas, conceituais e aplicadas (pp. 1-13). São Paulo: Roca.

Recebido em 24.11.2015

Primeira decisão editorial em 12.04.2016

Versão final em 25.05.2016

Aceito em 31.08.2016 